\title{
Stakeholder Perceptions of Offshore Wind Power: A Fuzzy Cognitive Mapping Approach
}

\author{
Kermagoret Charlène ${ }^{1,{ }^{*}}$, Levrel Harold ${ }^{2}$, Carlier Antoine ${ }^{3}$, Ponsero Alain ${ }^{4}$ \\ 1 IUEM, Université de Bretagne Occidentale, UMR AMURE, Brest, France \\ ${ }^{3}$ IFREMER, DYNECO, Laboratoire d'Ecologie Benthique, Technopole Brest-Iroise, Plouzané, France
}

${ }^{2}$ AgroParisTech, UMR CIRED, Nogent-sur-Marne, France

${ }^{4}$ Réserve Naturelle de la Baie de Saint-Brieuc, Hillion, France

* Corresponding author : Charlène Kermagoret

\begin{abstract}
:
Using the method of fuzzy cognitive mapping, this study explores stakeholder attitudes toward offshore wind energy. The survey was conducted with local communities of the Bay of Saint-Brieuc, where an offshore wind farm is under development. It was used to record the stakeholder perceptions of social, ecological, and economic impacts and the expression of expected compensation for negative impacts. Distribution and interaction among the data were analyzed through multiple correspondence analysis. Our study illustrates a gap between positive impacts associated with sustainable development perceived at the national level and more negative impacts perceived by local communities. The expression of expected compensation is dependent on the perceived impacts. This study highlights the place attachment of local stakeholders and thus suggests developing offshore wind farms with respect to territorial integrity and its heritage dimension in order to improve social acceptability.
\end{abstract}

Keywords : Bay of Saint-Brieuc, compensation principle, fuzzy cognitive mapping, impact perceptions, local communities, multiple correspondence analysis, offshore wind farm

\section{Acknowledgments}

This study contributes to the research project Interreg IVa-VALMER and to the call for project "Quels littoraux pour demain?" launched by the Fondation de France. The authors would like to thank these projects for funding this research. The authors would also like to thank all the stakeholders who took part in the survey for their time and contribution. Finally, the authors would like to thank the anonymous referees and editor for constructive comments on an earlier version of this paper. 


\section{Introduction}

In the current global context, both politicians and society as a whole have reached a consensus on the need to develop renewable energy (Wolsink, 2007). The choice to explore offshore wind energy is a fortunate thing, since this technology should partly meet environmental challenges and amend conflicts of practices that onshore wind farms have faced (Söderholm and Pettersson, 2011). Despite this ambition, offshore technology can also be a source of externalities for the host territory (Haggett, 2008). Ecological modifications, landscape amenities reduction, and the loss of exploitable marine areas are some of the sources of conflict that may compromise the development of this technology (Gill, 2005; Inger et al., 2009; Firestone et al., 2012). These local implications could explain the contradiction between a strong rate of acceptance at the national scale and more contrasted opinions within territories in which offshore wind farms are set up (Walker, 1995). This gap was originally related to the "Not In My Back Yard" (NIMBY) attitude but it turns out to be more complex and rather could be the result of the technocratic dimension and the top-down approaches of the projects, which involves a difficult consideration of local claims (Breukers and Wolsink, 2007; DevineWright, 2005; Wüstenhagen et al., 2007).

In France, several offshore wind farms are currently under development. Measures to offset the impacts of the projects are planned in order to restore a balance between the global dimension of the project, which only considers its positive effects (utility), and the local dimension, which considers both its positive and negative externalities (Gobert, 2010). These measures are defined on a regulatory basis or on the basis of voluntary agreements. On the one hand, the financial resources derived from an annual tax based 
1 on electricity production will benefit municipalities, fisheries committees and

2 sustainable development projects. Ecological compensation should also result from the

3 Environmental Impact Assessment legal framework. On the other hand, measures are

4 negotiated with local stakeholders to offset the losses they suffer. These measures can

5 take the form of different actions - financial compensation, investments in public goods, ecological restoration - and aim to maintain a certain level of well-being in the population and to increase the social acceptability of the projects (Kermagoret et al., 2014). Equivalence is sought between the losses suffered by users and the gain coming from compensation and we therefore require a better understanding of the impacts associated with installation of offshore wind farms in France and in the world.

The sources of impacts are heterogeneous within the population (Devine-Wright, 2009). The authors agree on the importance of visual impact, more precisely the industrialization of the landscape generated by the wind farms, as the main nuisance directly affecting local stakeholder place attachment (Krueger, 2007; Haggett, 2008; Westerberg et al., 2013). Moreover, perceived impacts on marine biodiversity determine to a greater extent the unfavorable opinions about offshore wind farm projects

Perceptions of these multiple and complex impacts lead to very contrasting attitudes

(Firestone and Kempton, 2007). On the other hand, employment created during the construction phase of the projects would cause positive perceptions. During the operational phase, job creation is more modest but may be developed by the establishment of benefit-sharing mechanisms and thus foster more positive perceptions about the projects (Ejdemo and Söderholm, 2015).

about offshore wind energy (Waldo, 2012; Ellis et al., 2007). Waldo (2012) characterizes 
1 three attitudes about Sweden offshore wind farms from in-depth interviews. One group has a positive feeling and highlights the positive effects of this technology on the global environment. A second group focuses on the landscape impact and highlights the project inefficiency and non-profitability. The third group is defined as "passive opponents" because they are against the project, but they do not take part in discussions. Similarly, Ellis et al. (2007) use the Q methodology ${ }^{1}$ to highlight the different stakeholder attitudes toward a projected offshore wind farm located on the Northern Irish coast. Some individuals reject the project because of these characteristics while others are opposed to this technology in general. Some individuals are focused on the visual impacts of the project while others are focused on broader impacts and still others put forward the aesthetic dimension of this new environment because of the originality of these new landscapes (Ellis et al., 2007).

This paper seeks to obtain a new perspective on stakeholder attitudes toward offshore wind energy, identifying the situations for which compensation is a suitable tool. The study uses the fuzzy cognitive mapping method that allows the respondent to organize and prioritize his speech using graphics support (Özesmi and Özesmi, 2004). The fuzzy cognitive mapping method offers a relevant methodological framework to compare the views of different groups of actors and to facilitate discussions during the interviews (Meliadou et al., 2012). This study focuses on local communities of the Bay of SaintBrieuc where an offshore wind farm is currently under development.

\footnotetext{
${ }^{1} \mathrm{Q}$ Methodology is a psychologic method developed to study people's subjectivity. The name "Q" comes from the form of factor analysis that is used to analyze the data. Normal factor analysis involves finding correlations between variables across a sample of subjects whereas $Q$ analysis looks for correlations between subjects across a sample of variables (Watts and Stenner, 2005).
} 
2 This French case study is of general interest since rapid development of offshore wind

3 farms is needed to ensure respect for the national energy goals. This implies the

4 acceptability and support of these projects by the local populations directly concerned.

5 Moreover, compensation is an important issue that is difficult for project leaders to

6 resolve because of the lack of methodological framework fixed by the state to define

7 appropriate compensation and because of the legal uncertainty around the

8 implementation and operation of these new technologies in France (Guéguen-Hallouët

9 et Boillet, 2012).

These results can be used to find appropriate compensatory measures and to improve the social acceptability of the projects. Indeed, the decision-making process will be more effective if a good understanding of stakeholder perceptions and expectations is established.

Materials \& methods

The planned offshore wind farm of the Bay of Saint-Brieuc

The Bay of Saint-Brieuc is one of the four sites selected for the implementation of offshore wind farms, following the publication of a first national call for tenders in July 2011 (Guéguen-Hallouët and Boillet, 2012). This project involves the deployment of 100 turbines (generating a total of $500 \mathrm{MW}$ ) spread over an area of $77 \mathrm{~km}^{2}$ situated at a minimum of $16.2 \mathrm{~km}$ from the coast. Different types of compensatory measures are 
1 already being considered by project leaders, including monetary incentives, the offering of public goods, and biodiversity offsets (Kermagoret et al., 2014).

The choice of an adequate compensatory scheme is conditioned by a minimum regulatory requirement which requires offsetting the negative ecological impacts that can not be avoided or reduced, the call for tenders' specifications requiring the establishment of compensation for the environment and the pre-existing uses on the territory and the need for social acceptance to complete the project.

\section{Sample selection: members of pre-identified local communities}

Our paper focuses on the local communities of the Bay of Saint-Brieuc which could be negatively affected by the project and which have not participated in the consultation process so far including: recreational users, members of an opponent collective, members of naturalist associations, and visitors. These communities have been identified by an analysis of the discourse carried out by institutional stakeholders of the Bay of Saint-Brieuc (Kermagoret et al., 2014). They cover a wide range of stakeholders who have different practices and different interests in the territory of the Bay of SaintBrieuc. From August 2012 to January 2013, 73 semi-structured interviews were conducted face-to-face on specific sites (touristic points of view, harbours) and during specific events ("Festival Natur'Armor"), and off-site, by appointment. More details about the sampled population are provided in Table 1. The community of recreational users includes members of associations or clubs, but also free practitioners of sailing, surfing, scuba diving, and recreational fishing. They use the Bay of Saint-Brieuc as an area to practice nautical activities because of its specific landscape and its physical and 
1 ecological characteristics (target species, species of interest, hydrology...). This

2 community includes residents living on the west, east, and south sides of the Bay. The naturalist community is structured around five associations sensitive to the protection of ecosystems of the bay. This community is careful to maintain a good ecological state and practices regular observation and monitoring of the local fauna and flora. The members of this community mainly reside on the west and south sides of the bay where the associations' headquarters are located. The opponent community is structured around a collective created against the project. It includes associations working for the preservation of local cultural and the natural heritage of the territory. This community is widely represented by secondary residents of the east side of the Bay of Saint-Brieuc. Unlike previously defined communities, the visitor population is not a well-constructed community because there are no strong interactions between its individuals. However, this group of people shares a common interest in the Bay of Saint-Brieuc or benefits from it, particularly through landscape amenities. These individuals don't live in the Bay of Saint-Brieuc but regularly go there to take advantage of its environment. Because of the size of our sample, we targeted only individuals who belong to one of these communities. Thus, in our sample there is no overlap in membership between the communities.

Table 1: Main characteristics of the sampled population

\section{Fuzzy cognitive mapping}

Articulation between qualitative and quantitative surveys is widely advocated to explore the factors influencing an individual's perceptions (Goeldner-Gianella and Humain- 
1 Lamoure, 2010). Fuzzy cognitive mapping is an appropriate method because of its semi-

2 quantitative approach (Mouratiadou and Moran, 2007). It was originally developed by psychology researchers and has subsequently been selectively applied in different disciplines, especially in the field of environmental research through systemic modeling, resource management, and participatory science (Papageorgiou, 2011). This method is a relevant tool for exploring the links between social norms, attitudes, and motivations driving individual preferences (Kontogianni et al., 2012). Originally, cognitive mapping was a qualitative modeling technique that describes the operation or representations of a system (Özesmi and Özesmi, 2004; Kok, 2009). It is based on concepts that are interconnected by causal relationships. The addition of the term "fuzzy" refers to the degree of causality linking the various concepts ("fuzzy weight"). It allows for a comparison of views of different stakeholders (Meliadou et al., 2012). It also enables the respondent to better structure their discourse and representations of the system, thereby ensuring the observer has a better understanding of the responses. Limitations of this method are the subjectivity of concepts and causalities expressed by the respondent and the potential different understanding of the exercise by the various respondents, which may bias the interpretation of the results (Meliadou et al., 2012). Kontogianni et al. (2012) recommend the use of fuzzy cognitive mapping in environmental economics for non-monetary or upstream assessments of a survey based on the choice experiment method.

Here, the fuzzy cognitive mapping method is used to describe the impacts and opportunities arising from the planned offshore wind farm in the Bay of Saint-Brieuc, as perceived by stakeholders. This allows us to define the corresponding compensatory measures. Each interview was organized into three sections in order to assess: (i) the 
1 degree of knowledge and involvement in the project, (ii) the perception of impacts (both

2 positive and negative), represented through a cognitive map, (iii) compensation expected to counterbalance the perceived negative impacts. Each individual must explain their choices and motivations. These qualitative data will allow us to clarify the results from the semi-quantitative analysis. From the second part of the questionnaire, respondents were invited to draw their own cognitive map that represents the positive and negative impacts (social, ecological, economic...) of the proposed wind farm on the territory of the Bay of Saint-Brieuc (Figure 1). Each expressed impact was represented by a word or by a group of words connected by an arrow with the central concept "Planned offshore wind farm in the Bay of Saint-Brieuc". Each arrow means "has an effect on" and is weighted by a causality link in an interval of [+3; -3$]$ which indicates if the effect is positive $(+)$ or negative $(-)$ and which represents the strength of this effect (1: weak; 2: medium; 3: strong). Causal links allow organization and ranking of the perceived effects of the project.

\section{Figure 1: An example of a cognitive map}

There are 410 variables defined as words or groups of words that constitute the 73 cognitive maps. Then, the 410 variables were grouped into 27 "reduced variables" by a semantic proximity criterion (Table 2). Aggregation of individual cognitive maps provides an overview of perceptions across all stakeholders and informs us about the origin of the heterogeneity of their perceptions of impacts and compensation. To make this aggregation possible, and the maps directly comparable, it is necessary to merge words and groups of words having the same meaning (semantic proximity) in order to develop a simplified classification based on the reduced variables (Prigent et al., 2008). 
1 For example, some people talk about landscape while others say visual impact to mention the same idea (Méliadou et al., 2012). A Multiple Correspondance Analysis (MCA) was used to explain the distribution of the perceived impacts and benefits. Sociodemographic factors were included as supplementary variables (see the list of these factors in Table 1). This step was performed by using the XLSTAT software package.

Table 2: List of the 27 reduced variables and citation frequencies in the overall sample

\section{Data sampling, complexity and heterogeneity of the cognitive maps}

At first, complexity of the cognitive maps is analyzed on the basis of the number of variables put forward in each map. On average, 5.6 variables per map have been expressed with the number of variables ranging from 1 to 14 . The distribution of this criterion within each community is presented in Figure 2.

Figure 2: Distribution of the number of variables listed in each cognitive map for the overall survey and for each community ["Mean complexity index" = number of variables per map; for each group, lines and crosses represent the mean and the median of variables, respectively]

These results are relatively close to those obtained by Prigent et al. (2008) and Kontogianni et al. (2012). The former study - conducted among 29 fishermen in order to evaluate their knowledge of the ecosystem - led to cognitive maps containing an average of 5 to 6 variables. The second study, conducted among 29 Ukrainian stakeholders in order to understand their perceptions about marine ecosystem risk, resulted in maps 
with 7.,86 variables on average. Ozesmi and Ozesmi (2004) made a list of studies using cognitive mapping in the field of environmental management and reported important numbers of variables per map in most of them (up to 32 variables in average). The number of expressed variables in each map is generally dependent on the knowledge of the subject of the questions (Eden et al., 1992). However, some authors advise caution during the interpretation of these densities and their intercomparison. For example Ozesmi and Ozesmi (2004) consider that the densities can depend on a number of factors such as interview duration or the learning of the exercise.

The duration of our interviews varied widely (from a quarter of an hour to an hour and a half, depending on the respondent). This variation is linked to the level of involvement and the knowledge of impacts by each stakeholder. The stronger the involvement and knowledge, the longer and more detailed the interview. This is the case for the opponent community and some of the naturalists involved in the project. However, the knowledge is much fuzzier and the involvement is almost non-existent for the visitor community, leading to less complex maps.

The mean causality index was calculated for each map and defined as the cumulative impact perceived. Overall, the average of the perceived cumulative impact in our sample is slightly negative $(-0,46)$ but values show a large dispersion (Standard Deviation $=1,7$ ) and their distributions vary widely among communities (Figure 3).

Figure 3: Distribution of the average causal links of each cognitive map for the sample and for each community ["Mean causality index" = mean causality per map; for each group, lines and crosses represent the mean and the median of variables, respectively] 
2 Our sample being limited to groups of stakeholders that are a priori impacted by the

planned offshore wind farm, it was expected that we would observe globally negative perceptions, i.e. a negative mean causality index. Although negative, the mean causality index is close to 0 and the data set shows a great disparity, meaning that impacts are distributed fairly evenly on both sides of the null value.

The opponent community differs from other groups by its significantly negative perception (only negative causality index). This result is logical since this community is the only community which is truly constituted and whose interest is markedly against the project. In contrast, visitors have an overall positive perception of the project although the average level of impact is very heterogeneous within this community (highest dispersion). This is explained by the greater diversity of individuals within the community and by the fact that their interests in relation to the territory and the project are not specified, in contrast with the others communities. To a lesser extent, recreational users have a negative perception which also reflects heterogeneous causalities within the community. Finally, naturalists have a slightly negative perception about the project. The absence of extreme values for the mean causality index for this community must be noted. This is explained by the difficulty of these individuals to have marked positions in their discourse. They perceive some potential impacts but have difficulty in assessing the strength of these impacts.

\section{Clustering of concepts}


1 Citation frequency of each reduced variable is presented in Table 3 . The 27 reduced

2 variables are organized according to aspects of development, governance, uses,

3 landscape, and natural resources. Some reduced variables, relatively broad, are

4 expressed frequently through cognitive maps as the concept of "ecosystem" (expressed

5 by $42.5 \%$ of respondents) and the concept of "landscape" (65.8\% of respondents). The

6 primary objective of the project, namely the production of electricity, is also widely

7 reported (35.6\% of respondents). More specific issues also seem to mobilize

8 perceptions: impacts on tourism, fishing, and birds. We will see below how these terms

9 are used (in a negative or positive way) and how their occurrence is distributed in the sampled population.

\section{Results and discussion}

\section{Distribution and interaction among variables through Multiple_Correspondence}

Analysis (MCA)

Variables used for the MCA are presented in Table 3 and the results are presented in

Figure 4. Figure 4 indicates association between five groups of parameters: reduced variables, causalities, expected compensation, local communities and socio-demographic characteristics. The interpretation of the variables is based on the relative distance between them and on their position with respect to the main axes. The points located at both ends of a given axis are opposing variables. The variables that are close to each other are involved in the interpretation of homogeneous groups of perceptions.

Table 3: Variables and modalities for the multiple correspondence analysis 
Figure 4: A two-dimensional solution of MCA explaining the distribution of perceived impacts through the sample (O: reduced variables; $\square$ : causalities; X: expected

compensation; $\Delta$ : local communities; •: socio-demographics characteristics)

The $\mathrm{x}$-axis of the biplot in Figure $4(\mathrm{~F} 1=33,7 \%$ of the total variance) follows an increasing causality gradient and discriminates causalities with negative values on the left (causality $<0$ ) from those with positive values on the right (causality $>0$ ). This axis can be mainly interpreted as the axis of opposition between positive and negative perceptions in terms of perceived impact of the planned offshore wind farm. The further the variables are from the origin point, the stronger the perceived impacts for individuals. The $\mathrm{y}$-axis (F2 $=13 \%$ of the variance) is mainly interpreted as the opposition axis between the expression of a compensation refusal ("No" variable) and a potential expectation of compensation ("Yes" and "No opinion" variables). While no compensation is expected for variables located above the origin of the $y$-axis, compensatory measures are potentially considered for the variables located below the origin of the $y$-axis. We have integrated in this latter case, the "No opinion" expression about compensation because it does not reflect a categorical rejection of the compensation principle but is rather the result of the difficulty for stakeholders in considering how impacts can be offset.

The distribution of reduced variables in Figure 4 reveals three main groups of variables. First, because they are located above the origin point of the $\mathrm{x}$-axis, the variables which refer to the development aspects of the project, more specifically sustainable development, have very positive connotations. The groups of variables located above the 
origin of the y-axis are associated with a compensation refusal, which is logical since compensation seeks to mitigate negative impacts in order to maintain a constant level of well-being. In contrast, the issues concerning project governance (consultation, local policies) and the costs of the project are perceived as the most negative on the plot, located below the origin point of the x-axis, but are also linked to a compensation refusal, located above the origin of the y-axis. In this latter case, the expression of a compensation refusal is stronger than the previous case and is explained by the difficulty in defining appropriate compensatory measures for those impacts, as they are perceived as coming from the governance process and not from the project itself. Compensation does not appear to be an appropriate tool to mitigate these latter issues. Lastly, impacts on uses and natural resources are also perceived rather negatively, even if the latter seems to be somewhat balanced due to a potential colonization of the new hard substrate by marine organisms, called the "reef effect". Both these impacts are subject to possible compensation but such compensation is not claimed at this stage for two reasons. First, respondents have difficulty in representing the nature and the extent of impacts generated by the offshore wind farm since it is still at the project stage. Second, respondents are unaware of the availability of compensation and the various measures that can be implemented.

Distribution of reduced variables and the possible relationships between them can be summarized as follows. The projected offshore wind farm is a vector of positive perceptions, since it fits within public policies for sustainable development. However, the project directly acts on the environmental components by generating externalities that are perceived by the local communities. On the one hand, the potential reef effect can provide positive externalities on the ecosystem. On the other hand, negative 
externalities are expected on the landscape and ecosystem components (benthos, birds, exploited resources...) during the construction and exploitation stages of the offshore wind farm. The latter will have the consequence of affecting the well-being of the users of the bay. The perceived impacts on both the natural resources and uses could be addressed by appropriate governance tools, which should be part of the project management.

Compensatory measures can be envisioned at different levels and can take different forms. The implementation of environmental compensation measures would offset environmental externalities to maintain an ecological equity on the territory by directly targeting the affected components of the ecosystem. For example this could take the form of a restoration of ecological habitats (Dunford et al., 2004). This environmental compensation, by a domino effect, could increase users' positive perceptions about the Bay of Saint-Brieuc. The implementation of economic compensation measures would guarantee employment in the territory through monetary incentives and support measures for specific sectors. The implementation of social compensation measures would maintain a level of well-being for users and inhabitants by targeting individuals directly impacted by the negative externalities of the project, in the form of monetary incentives for example.

\section{Characterization of the local communities' attitudes}

The position of local communities (Figure 4) and their distance to reduced variables allows the characterization of each community by its relation to its perceptions of the system. The distribution of local community members is shown in Figure 5 and gives 
1 some information on the heterogeneity within each group. Finally, the origin point of the biplot corresponds to a relatively neutral attitude, where negative, positive, social, environmental, and economic impacts are balanced. The four communities are distributed differently around the origin point. Figure 5 shows that these communities are composed partly by individuals who a neutral attitude and partly by individuals who possess marked attitudes located farther from the origin point on the plot.

Figure 5: Distribution of local communities' members according to the first two axes of the MCA (o: local communities' members; $\square$ : causalities; X: expected compensation; reduced variables and socio-demographics characteristics are not shown)

Visitors have a very positive perception of impacts related to the opportunities of sustainable development in relation to the project (Figure 4). Expressed variables rely more on a generally positive opinion about wind power at the national scale than on local issues. This can be explained by a weaker attachment to the territory for these individuals than for other communities and by a less extensive knowledge of the project and of its impacts. This leads to more weakly built perceptions. This group does not clearly express a claim for compensation, which seems natural in view of the perceived positive impacts.

Naturalists have a general perception about impacts that is close to zero, reflecting a balance between impacts considered as negative and positive effects of renewable energy production, both focused on natural resources (Figure 4). The main fear of naturalists concerns birds because of the potential destruction of their feeding zone and the potential disruption of migration. These users widely give a "no-opinion" answer 
concerning the expectation of compensation. The main explanation for this result is that naturalists do not feel it is appropriate to express themselves on the compensation principle, which, in their opinion, could only be adequately evaluated from the completion of the Environmental Impact Assessment study. The results of this study being unknown at the time of the survey, most naturalists will not express themselves on the need for compensation. Compensatory measures would be expected only in the case on which residual ecological impacts remain after the deployment of avoidance and mitigation measures.

Recreational users have a slightly negative perception about impacts, focused on the landscape and ecosystem components and the pre-existing uses of the bay (Figure 4). These users are the closest to the expression of a compensation claim focused on no-netloss of well-being.

Opponents have a very negative perception of impacts, focused on governance issues and costs of the project (Figure 4). The group rejects the idea of compensation because, on one hand, compensation would increase the cost of the project: these individuals hold the perception that this is an expensive project at the national level. Thus compensatory measures cannot alleviate this perception. On the other hand, impacts are difficult to offset. The levers to offset the impacts they perceive and also to increase the social acceptability of this community are a large part of the consultation process with local stakeholders.

Because of their central position in the plot in Figure 4, socio-demographic characteristics such as age and gender don't affect the distribution of the reduced 
variables within the plot. The residence area is a more distinguished factor but is linked to different communities.

\section{Points of convergence between communities perceptions}

Finally, it is also interesting to study the points of convergence between these different communities, even if they at first appear well distinguished. In Figure 4, some variables appear at the interface of several local communities. Thus, the reduced variables "employment", "landscape" and "ecosystem" are expressed by all the communities and constitute important issues. The broad "ecosystem" concept incorporates expressed variables relative to the flora and fauna and, biodiversity, and covers most sources of potential impacts. This fuzziness reveals the difficulty of individuals to picture such impacts, except for the naturalists who clearly perceive specific issues concerning the avifauna. Communication about ecological impacts and transparency regarding the results of the impact assessment study to define appropriate compensation will be an important lever for acceptability. The concept of "landscape" is highly mobilized by all communities. It directly refers to conceptualizations of a "sense of place" and place attachment. Even if the net effect is globally negative, it covers contrasting perceptions between those who see it as a negative impact, those who imagine it as a very marginal impact and, finally, those who appreciate the turbines as new elements in the landscape. Information on this issue can also be seen as a lever to facilitate discussions between developers and stakeholders since it includes indirect impacts on recreational use, the living environment of residents, and tourism. Employment mobilizes many perceptions and is a real issue for the acceptability of the project. This central position also revealed some contrasting perceptions which reflect the fact that some people believe in job 
creation through the maintenance of the wind farm while some believe that job creation will be extremely low. Others fear a destruction of existing jobs based on the activities already in place (tourism and fishing industries). Creating new jobs and maintaining the existing ones can be a true lever towards the social acceptability of the project.

\section{Conclusion}

In conclusion, the findings make an original contribution to the literature dealing with human aspects of offshore wind technologies (see Wolsink, 2007 ; Haggett, 2008), and emphasize the multiple and complex attitudes of local communities towards offshore wind development. The study highlights the contrast between a national vision and a local vision about offshore wind farms, and provides new understanding to characterize the gap between the two (Devine-Wright, 2005). The national vision is supported by positive arguments in favor of sustainable development that are widely expressed by individuals who reside outside of the territory. The local vision brings out some negative convictions related to local issues such as project governance, natural resources, landscape, and recreational uses, which are expressed by the local communities. Thus, the study highlights the place attachment for stakeholders and suggests developing offshore wind farms with respect to territorial integrity and its heritage dimension. Beyond these results, the study makes an interesting contribution to the existing literature by directly questioning the suitability of the compensation principle for increasing the social acceptability of the project. Thus, the results shows that, depending on community attitudes, compensation may, (i) not be required since no negative impact is perceived; (ii) not be the appropriate tool, and emphasis should instead be put on the consultation process, or alternatively (iii) be a substantial lever for social acceptability 
1 since negative socio-ecological impacts are perceived. However, when the compensation

2 principle seems suitable, the discourse is vague on how this tool must be employed.

3 Respondents have difficulties agreeing on who should be the beneficiaries of

4 compensation and what type of actions should be implemented. The authors suggest

5 that future research should discuss the desirability of different compensatory measures

6 such as financial compensation, investments in public goods, and ecological restoration,

7 in order to maintain a level of well-being in the population by exploring the preferences

8 for suitable methods.

9

More generally, the authors suggest an increase in the amount of empirical studies on attitudes about offshore wind and the compensation principle in order to improve the robustness of the results. These studies are all the more relevant as the compensation principle tends to become institutionalized both at European and global levels.

\section{$\underline{\text { References }}$}

Breukers, S., and M. Wolsink. 2007. Wind power implementation in changing institutional landscapes: An international comparison. Energy Policy 35(5): 2737-2750.

Devine-Wright, P. 2005. Beyond NIMBYism: towards an Integrated Framework for

Understanding Public Perceptions of Wind Energy. Wind Energy 8(2): 125-139

Dunford, R., T. Ginn, and W. Desvousges. 2004. The use of habitat equivalency analysis in natural resource damage assessment. Ecological Economics 48(1): 49-70.

Eden, C., F. Ackermann, and S. Cropper. 1992. The analysis of cause maps. Journal of

Management Studies 29(3): 309-324. 
1 Ejdemo, T., and P. Söderholm. 2015. Wind power, regional development and benefitsharing: The case of Northern Sweden. Renewable \& Sustainable Energy Reviews 47: $476-485$

Ellis, G., J. Barry, and C. Robinson. 2007. Many ways to say 'no', different ways to say 'yes': Applying Q Methodology to understand public acceptance of wind farm proposals. Journal of Environmental Planning and Management 50(4): 517-551.

Firestone, J., and W. Kempton. 2007. Public opinion about large offshore wind power : underlying factors. Energy Policy 35(3): 1584-1598.

Firestone, J., W. Kempton, M.B. Lilley, and K. Samoteskul. 2012. Public acceptance of offshore wind power across regions and through time. Journal of Environmental Planning and Management 55(10): 1369-1386.

Gill, B. 2005. Offshore renewable energy : ecological implications of generating electricity in the coastal zone. Journal of Applied Ecology 42(4): 605-615.

Gobert, J. 2010. Ethique environnementale, remédiation écologique et compensations territoriales. VertigO - La revue en sciences de l'environnement 10(1) : 1-13.

Goeldner-Gianella, L., and A.-L. Humain-Lamoure. 2010. Les enquêtes par questionnaire en géographie de l'environnement. L'Espace géographique 39(4): 325-344.

Gueguen-Hallouet, G., and N. Boillet. 2012. L’appel d'offres "éolien en mer". Quelques réflexions à propos d'un nouvel avatar juridique. La Semaine juridique - Administrations et collectivités territoriales $40: 27-34$.

Haggett, C. 2008. Over the Sea and Far Away? A Consideration of the Planning, Politics and Public Perception of Offshore Wind Farms. Journal of Environmental Policy \& Planning 10(3): 289-306.

Inger, R., M. Attrill, S. Bearhop, A. Broderick, W.J. Grecian, D. Hodgson, C. Mills, E. Sheehan, S. Votier, M. Witt, and B. Godley. 2009. Marine renewable energy : potential 
1 benefits to biodiversity? An urgent call for research. Journal of Applied Ecology 46(6):

2

3

4 1145-1153.

Kanbur, R. 2003. Economie du développement et principe de compensation. Revue internationale des sciences sociales 175: 29-38.

Kermagoret, C., H. Levrel, and A. Carlier. 2014. The impact and compensation of offshore wind farm development in France: How institutional stakeholders characterise their perceptions. Scottish Geographical Journal 130(3): 188-206

Kok, K. 2009. The potential of Fuzzy Cognitive Maps for semi-quantitative scenario development with an example from Brazil. Global Environmental Change 19(1): 122133.

Kontogianni, A., E. Papageorgiou, L. Salomatina, M. Skourtos, and B. Zanou. 2012. Risks for the Black Sea Marine Environment as Perceived by Ukrainian Stakeholders: A Fuzzy Cognitive Mapping Application. Ocean \& Coastal Management 62: 34-42.

Krueger, A. 2007. Valuing Public Preferences for Offshore Wind Power. Dissertation, Doctor of Philosophy in Marine Studies,University of Delaware, Newark, Delaware, USA.

Meliadou, A., F. Santoro, M. Nader, M. Abou Dagher, S. Al Indary, and B. Abi Salloum 2012. Prioritising coastal zone management issues through fuzzy cognitive mapping approach. Journal of Environmental Management (97) p.56-68

Mouratiadou, I., and D. Moran. 2007. Mapping public participation in the Water Framework Directive: A case study of the Pinios River Basin, Greece. Ecological Economics 62(1): 66-76.

Özesmi, U., and S. Özesmi. 2004. Ecological models based on people's knowledge: a multi-step fuzzy cognitive mapping approach. Ecological Modelling 176 (1-2): 43-64. 
1 Papageorgiou, E. 2011. Review study on Fuzzy Cognitive Maps and their applications

2 during the last decade. International Conference on Fuzzy Systems, June 27-30, 2011,

3 Taipei, Taiwan.

4 Prigent M., G. Fontenelle, M. lle Rochet, and V. Trenkel. 2008. Using cognitive maps to 5 investigate fishers' ecosystem objectives and knowledge. Ocean \& Coastal Management $6 \quad 51(6): 450-462$

7 Quétier F., and S. Lavorel. 2012. Assessing ecological equivalence in biodiversity offset 8 schemes: Key issues and solutions. Biological Conservation 144(12): 2991-2999.

9 Söderholm, P., and M. Pettersson. 2011. Offshore wind power policy and planning in Sweden. Energy Policy 39(2): 518-525.

Waldo, A. 2012. Offshore wind power in Sweden - A qualitative analysis analysis of attitudes with particular focus on opponents. Energy Policy 41: 692-702.

Walker, G. 1995. Renewable energy and the public. Land Use Policy 12(1): 49-59.

Watts, S., and P. Stenner. 2005 Doing Q methodology: Theory, method and interpretation. Qualitative Research in Psychology 2(1): 67-91.

Westerberg, V., J. Jacobsen, and R. Lifran. 2013. The Case for Offshore Wind Farms, Artificial Reefs and Sustainable Tourism in the French Mediterranean. Tourism Management 34: 172-183.

Wolsink, M. 2007. Planning of renewables schemes: Deliberative and fair decisionmaking on landscape issues instead of reproachful accusations of non-cooperation. Energy Policy 35(5): 2692-2704.

Wüstenhagen, R., M. Wolsink, and M. Bürer. 2007. Social Acceptance of Renewable Energy Innovation: An Introduction to the Concept. Energy Policy 35(5): 2683-2691. 